\title{
Oxygen Tension Strongly Influences Metabolic Parameters and the Release of Interleukin-6 of Human Amniotic Mesenchymal Stromal Cells In Vitro
}

\author{
Asmita Banerjee $\left(\mathbb{D},{ }^{1,2}\right.$ Andrea Lindenmair $\left(\mathbb{D},{ }^{2,3}\right.$ Ralf Steinborn $(\mathbb{D})$, \\ Sergiu Dan Dumitrescu $\mathbb{D}^{1},{ }^{1,2}$ Simone Hennerbichler ${ }^{(D},^{5}$ Andrey V. Kozlov ${ }^{D},{ }^{1,2}$ \\ Heinz Redl $\mathbb{D}^{1,2}$ Susanne Wolbank $\mathbb{D}^{1,2}$ and Adelheid Weidinger $\mathbb{D}^{1,2}$ \\ ${ }^{1}$ Ludwig Boltzmann Institute for Experimental and Clinical Traumatology, AUVA Research Center, Donaueschingenstraße 13, \\ 1200 Vienna, Austria \\ ${ }^{2}$ Austrian Cluster for Tissue Regeneration, Vienna, Austria \\ ${ }^{3}$ Ludwig Boltzmann Institute for Experimental and Clinical Traumatology, AUVA Research Center, Garnisonstraße 21, \\ 4020 Linz, Austria \\ ${ }^{4}$ Genomics Core Facility, VetCore, University of Veterinary Medicine, Veterinaerplatz 1, 1210 Vienna, Austria \\ ${ }^{5}$ Red Cross Blood Transfusion Service for Upper Austria, Krankenhausstraße 7, 4017 Linz, Austria
}

Correspondence should be addressed to Asmita Banerjee; asmita.banerjee@trauma.lbg.ac.at

Received 12 February 2018; Revised 18 May 2018; Accepted 6 September 2018; Published 28 October 2018

Academic Editor: Hannele T. Ruohola-Baker

Copyright $\odot 2018$ Asmita Banerjee et al. This is an open access article distributed under the Creative Commons Attribution License, which permits unrestricted use, distribution, and reproduction in any medium, provided the original work is properly cited.

The human amniotic membrane (hAM) has been used for tissue regeneration for over a century. In vivo (in utero), cells of the hAM are exposed to low oxygen tension ( $1-4 \%$ oxygen), while the hAM is usually cultured in atmospheric, meaning high, oxygen tension (20\% oxygen). We tested the influence of oxygen tensions on mitochondrial and inflammatory parameters of human amniotic mesenchymal stromal cells (hAMSCs). Freshly isolated hAMSCs were incubated for 4 days at $5 \%$ and $20 \%$ oxygen. We found $20 \%$ oxygen to strongly increase mitochondrial oxidative phosphorylation, especially in placental amniotic cells. Oxygen tension did not impact levels of reactive oxygen species (ROS); however, placental amniotic cells showed lower levels of ROS, independent of oxygen tension. In contrast, the release of nitric oxide was independent of the amniotic region but dependent on oxygen tension. Furthermore, IL-6 was significantly increased at $20 \%$ oxygen. To conclude, short-time cultivation at $20 \%$ oxygen of freshly isolated hAMSCs induced significant changes in mitochondrial function and release of IL-6. Depending on the therapeutic purpose, cultivation conditions of the cells should be chosen carefully for providing the best possible quality of cell therapy.

\section{Introduction}

Oxygen is the element of highest electronegativity after fluorine, and even molecular oxygen is still a highly reactive and therefore, toxic molecule. Photosynthesis by organisms in early evolution led to the "oxygen explosion" in the earth's atmosphere 2.3 billion years ago, causing mass extinction of anaerobic species $[1,2]$. By hypothesis, only the entering of an oxygen-utilizing prokaryote into a preeukaryote allowed surviving an oxygen-containing atmosphere [3]. This process of endosymbiosis, marking the birth of mitochondria, changed the course of evolution [3] (reviewed in [4]).

Tissue oxygen tension is a measure of the oxygen partial pressure in the interstitial (extravascular) space reflecting the balance between oxygen supply and demand (reviewed in [5]). Oxygen tension in cellular microenvironment can strongly influence cellular processes (reviewed in [6]). In the course of evolution, organisms developed numerous strategies to cope with the potentially toxic effects of oxygen, such as antioxidant systems and enzymes. Exposure to 
oxygen in tissues is therefore highly regulated by the level of vascularization (reviewed in [5]). Mammalian tissues have highly specific oxygen tensions which can range from $16 \%$ oxygen in alveolar air (reviewed in $[5,7]$ ) down to almost anoxic calculated oxygen tension in the bone marrow hematopoietic compartment $[8,9]$. Therefore, different cells of the body are exposed to different oxygen tensions. Adult stem cells, such as mesenchymal stem cells, neural stem cells, and hematopoietic stem cells, maintain their stem cell state in niches of very low oxygen tensions (reviewed in [10, 11]). An increasing number of publications have demonstrated energy supply via glycolysis in embryonic $[12,13]$ (reviewed in [14]) and mesenchymal stem cells [15-18] and even induced pluripotent stem cells (iPSCs) [19]. According to current models, stem cells remain quiescent in their specialized niche [20] (reviewed in [21, 22]) until external signals induce a metabolic shift. Stem cells then switch their metabolism from primarily glycolytic to oxidative phosphorylation and start to differentiate towards progenitor and precursor cells (reviewed in [23]). Therefore, it is now widely accepted that maintenance of a stem cell state requires maintenance of their highly specific microenvironment.

An attractive source of adult stem cells is the human amniotic membrane (hAM) [24]. This fetal membrane consists of an epithelial layer, formed by a monolayer of human amniotic epithelial cells (hAECs), and a collagen-rich mesenchymal layer, in which the human amniotic mesenchymal stromal cells (hAMSCs) are embedded. In clinics, the hAM has been used decellularized or denuded for tissue regeneration purposes for over a century $[25,26]$. Transplanted hAM does not cause rejection reactions in the patient (reviewed in [27]), and furthermore, the hAM and the cells thereof have anti-inflammatory [28-36] and immunomodulatory properties [37-39]. Additionally, cells of the hAM can differentiate into cells of all three germ layers in vitro and in vivo [4044]. Therefore, the use of cells of the hAM for tissue regeneration has moved into the focus of many research groups.

While common cell culture conditions derive originally from cultivations of chicken fibroblasts at $20 \%$ oxygen, other cells, such as stem cells, need a more specialized oxygen microenvironment. Changes in the oxygen microenvironment particularly affect mitochondria, also designated as the "main sink of oxygen" [45]. Oxygen, with its high standard redox potential, is the final electron acceptor in the mitochondrial electron transport chain for the generation of adenosine triphosphate (ATP) via oxidative phosphorylation. This metabolic process also releases superoxide, a reactive oxygen species (ROS), predominantly produced by mitochondrial complexes I and III $[46,47]$. ROS, formerly considered as mere damaging byproducts, came recently into focus for their signalling function (reviewed in [48]). Therefore, it does not come as a surprise that mitochondrial function plays a critical role in maintaining stemness [49], orchestrates cell fate (reviewed in [23]), and also plays a critical role for tissue regeneration [50].

In vivo, cells of the hAM are exposed to low oxygen tension (1-4\%; [51]) while in vitro cultivation or storage is usually performed at $20 \%$ oxygen. As changes in the microsurroundings of hAMSCs in culture may impact cellular processes, we tested the influence of low (5\%) and high (20\%) oxygen tensions on mitochondrial function of freshly isolated hAMSCs after 4 days in culture. As we found different mitochondrial activities in reflected and placental amnion biopsies in a former study [52], we separately investigated hAMSCs from placental (P-hAMSCs) and reflected amnion (RA-hAMSCs). Furthermore, as the antiinflammatory properties of the hAM represent a potentially crucial function in a clinical transplantation situation, we also measured parameters linked to inflammation. The results of this study could support the possibility of specific selection and preparation of amniotic cells according to clinical requirements.

\section{Material and Methods}

2.1. Preparation of the Human Amniotic Membrane. Placentae were obtained from planned caesarean sections from healthy patients at full term. The patients had signed informed consent with approval of the local ethics committee, in accordance to the Declaration of Helsinki. Placentae were transported within 4 hours of delivery, in $500 \mathrm{~mL}$ Ringer solution. Placentae from caesarean sections of premature deliveries, emergency caesarean sections, and placentae with detached amniotic membranes were excluded from the study. The reflected and placental regions of the hAM were separated from each other as previously described [52].

\subsection{Isolation of Human Amniotic Mesenchymal Stromal} Cells. Isolation of hAMSCs was performed as previously described [33]. Briefly, reflected and placental amnions were cut into $2 \times 2 \mathrm{~cm}$ pieces, incubated in $1 \mathrm{mg} / \mathrm{mL}$ collagenase solution, and shaken for $2 \mathrm{~h}$ at $37^{\circ} \mathrm{C}$. Digestion was stopped with cold PBS, and the cell suspension was filtered through $100 \mu \mathrm{m}$ cell strainers and centrifuged at $4^{\circ} \mathrm{C}$ for $9 \mathrm{~min}$ at $400 \mathrm{~g}$. The cell pellet was resuspended in DMEM, supplemented with 10\% FCS, $2 \mathrm{mM}$ L-glutamine, and $1 \%$ penicillin/streptomycin (medium and supplements from Sigma-Aldrich, USA). Cell yields of approximately $15 \times 10^{6}$ cells for reflected amnion and $10 \times 10^{6}$ cells for placental amnion were reached per donor, depending on the size of the hAM. Donors with more than $10 \%$ dead cells (staining positive for trypan blue) were excluded from the study.

\subsection{Cultivation of Human Amniotic Mesenchymal Stromal} Cells at 5\% and 20\% Oxygen. Freshly isolated hAMSCs of both amniotic regions, reflected and placental, were cultured for 4 days at $37^{\circ} \mathrm{C}$, humidified atmosphere, $5 \% \mathrm{CO}_{2}$, and $5 \%$ or $20 \% \mathrm{O}_{2}$. The cell culture medium, DMEM, was supplemented with $10 \%$ FCS, 1\% penicillin/streptomycin, 1\% Lglutamine (medium and supplements from Sigma-Aldrich, USA), and $20 \mathrm{mM}$ HEPES (Gibco ${ }^{\mathrm{TM}}$, USA). Prior to incubation at $5 \% \mathrm{O}_{2}$, the cell culture medium was purged with medicinal $\mathrm{N}_{2}$, in order to replace the oxygen dissolved in the medium. The decrease of $\mathrm{O}_{2}$ level was confirmed with Blood Gas Analyzer Radiometer ABL800 Flex (Radiometer, Denmark). Samples for all measurements described below were taken at day 0 or after 4 days incubation at 
$5 \%$ or $20 \% \mathrm{O}_{2}$ without additional passaging. Therefore, all cells were measured directly in passage 0 or after detachment of passage 0 .

2.4. Measurement of Mitochondrial Activity. Mitochondrial respiration of isolated hAMSCs was measured with highresolution respirometer (Oxygraph-2k, Oroboros Instruments, Austria). At day 0, freshly isolated hAMSCs were seeded with a density of $20,000-30,000 \mathrm{cells} / \mathrm{cm}^{2}$ and incubated at oxygen tensions of $5 \%$ or $20 \%$. At day 4 , the cells were detached and counted. For measurement of ROUTINE respiration, $4 \times 10^{6}$ hAMSCs were resuspended in DMEM at $\mathrm{pH} 7.2$ and $37^{\circ} \mathrm{C}$. For measurement of LEAK respiration, ATP synthase was inhibited with $1 \mu \mathrm{M}$ oligomycin (SigmaAldrich, USA). Maximum electron transfer system capacity was measured by titration of carbonyl cyanide-4-(trifluoromethoxy)phenylhydrazone (FCCP, Sigma-Aldrich, USA) in steps of $0.5 \mu \mathrm{M}$. Phosphorylation-related respiration was calculated by subtraction of LEAK respiration from ROUTINE respiration (Supplemental Figure 1). Analysis of the data was performed by calculating the slopes of the oxygen concentration curves with Microsoft Excel (Version 14.0.7190.5000 (32 bit)). Sample numbers (biological replicates) $n=5-7$.

2.5. Measurement of Lactate Concentrations. Lactate concentrations were quantified in the cell culture supernatants of 100,000 cells $/ \mathrm{mL}$ after 4-day incubation of reflected and placental hAMSCs with Blood Gas Analyzer Radiometer ABL800 Flex (Radiometer, Denmark). Sample numbers (biological replicates) $n=4$.

2.6. Adenosine Triphosphate (ATP) Measurement. The samples for measurement of ATP were taken either from freshly isolated hAMSCs or from hAMSCs after cultivation for 4 days at $5 \%$ or $20 \%$ oxygen. 100,000 cells were pelleted, snap frozen in liquid nitrogen, and stored at $-80^{\circ} \mathrm{C}$. The cells were homogenized in Precellys tubes with ceramic beads (Keramik-Kit $1.4 \mathrm{~mm}$ Peqlab VWR, USA) in a ball mill (CryoMill MM301, Retsch, Germany) with $500 \mu \mathrm{L}$ of Tris$\mathrm{HCl}$ Buffer (20 mM Tris, $135 \mathrm{mM} \mathrm{KCl,} \mathrm{pH} \mathrm{7.4).} \mathrm{To} 100 \mu \mathrm{L}$ homogenate, $400 \mu \mathrm{L}$ of boiling $100 \mathrm{mM}$ Tris $/ 4 \mathrm{mM}$ EDTA Buffer ( $\mathrm{pH}$ 7.75) was added and incubated for $2 \mathrm{~min}$ at $100^{\circ} \mathrm{C}$ and centrifuged at $1000 \mathrm{~g}$ for $2 \mathrm{~min}$. ATP was determined by ATP Bioluminescence Assay Kit CLS II (Roche, Switzerland) using luciferase reagent with Luminat LB 9507 (Berthold, Germany). Sample numbers (biological replicates) $n=3-5$.

2.7. Determination of Mitochondrial DNA (mtDNA) Copy Number. Cellular DNA was extracted from a pellet of 10,000 hAMSCs using the Tissue \& Cell Genomic DNA Purification Kit in accordance with the manufacturer's protocol (GMbiolab Co., Taiwan). The ratio of mtDNA to nDNA was determined as an estimate for the number of mitochondrial genomes per cell using quantitative PCR assays against the single-copy nuclear gene $M Y C$ and the gene MT-ND1 representing the minor arc of the mitochondrial genome [53] (Supplemental Table 1). Sample numbers (biological replicates) $n=5$. The $\mathrm{Cq}$ values measured by quantitative PCR were transformed into copy numbers using digital PCR [53].

2.8. Reactive Oxygen Species. Electron paramagnetic resonance (EPR) spectra from frozen samples $(100,000$ cells) were recorded by Miniscope MS200 EPR spectrometer (Magnettech Ltd., Germany) at $-196^{\circ} \mathrm{C}$ (modulation frequency $100 \mathrm{kHz}$, microwave frequency $9.429 \mathrm{GHz}$, microwave power $30 \mathrm{~mW}$, modulation amplitude $5 \mathrm{G}$ ) as previously described [53]. Intensities of oxidized cyclic hydroxylamine 1-hydroxy3-carboxy-2,2,5,5-tetramethylpyrrolidine hydrochloride CP$\mathrm{H}$ (3-CP, Noxygen, Germany) signals were recorded at $3359 \pm 200 \mathrm{G}$ and quantified by single integrating the low field peak of the 3-CP signal, as previously described [54]. Sample numbers (biological replicates) $n=4$.

2.9. Nitric Oxide Concentration in the Supernatant. Total nitric oxide (NO) levels in the cell culture supernatants of 100,000 cells/mL were analyzed with Sievers $280 \mathrm{i}-\mathrm{NO}$ Analyzer (General Electrics) as previously described [55]. Briefly, plasma samples were injected through a septum into the glass vessel, where $\mathrm{NO}$ species were converted by $\mathrm{VCl}_{3}$ to $\mathrm{NO}_{(\mathrm{g})}$. A subsequent chemiluminescent reaction with $\mathrm{O}_{3}$ caused photon emission, which was converted and displayed as the voltage signal after detection with photomultiplier. Sample numbers (biological replicates) $n=5$.

2.10. Release of Immunoactive Substances. Interleukin- (IL-) $1 \beta$, IL-6, IL-10, and hepatocyte growth factor (HGF) concentrations were detected in the cell culture supernatant of 100,000 cells $/ \mathrm{mL}$ after 4 -day incubation of hAMSCs at 5\% $\mathrm{O}_{2}$ and $20 \% \mathrm{O}_{2}$ with the immunoassay ProcartaPlex ${ }^{\mathrm{TM}}$ Human Basic Kit (Thermo Fisher Scientific, Invitrogen, USA), using antibody-coated magnetic beads (Luminex ${ }^{\mathrm{TM}}$ ). Measurement was performed according to the manufacturers' protocol, and absorption was measured with BioPlex 200 instrument (Bio-Rad Laboratories, USA). Sample numbers (biological replicates) $n=6$.

2.11. Statistical Analysis. Data was analyzed using GraphPad Prism software (GraphPad Software, USA). For analysis of day 0 versus day 4, one-way ANOVA was used, followed by the Bonferroni post hoc test in normally distributed data and Kruskal-Wallis combined with Mann-Whitney test in groups showing a non-Gaussian distribution. The Wilcoxon matched pairs test was used to analyze differences in mtDNA copy numbers. Paired $t$-test was used to analyze differences between amniotic regions (reflected versus placental amnion) and oxygen tensions (5\% versus 20\% oxygen). In all tests, $n$ (sample size) represents the number of biological replicates (donors). Results are presented as mean \pm SD for normally distributed data. Copy numbers of cellular mtDNA are presented as scatter dot plots. Level of significance was set at 0.05 and is indicated as ${ }^{*} p<0.05$, ${ }^{* *} p<0.01$, and ${ }^{* * *} p<0.001$.

\section{Results}

3.1. Measurement of Mitochondrial Activity and Glycolysis. To assess the impact of different oxygen tensions on the 


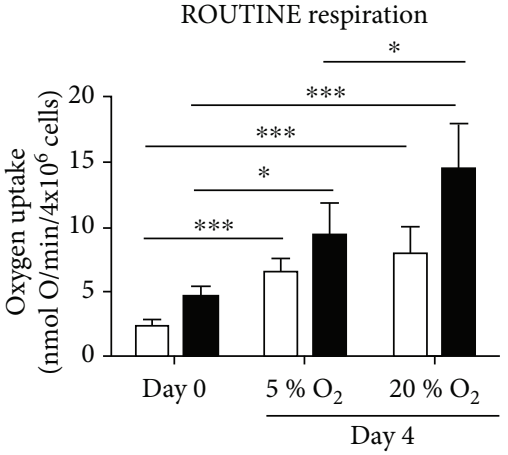

(a)

Phosphorylation-related respiration

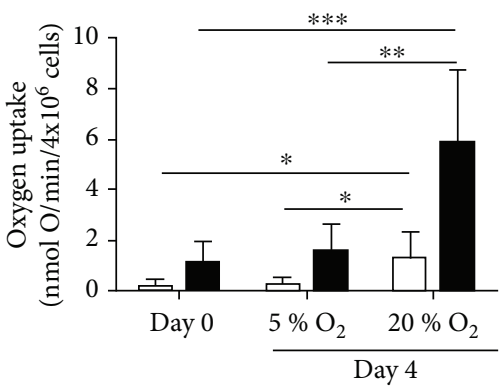

$\square$ Reflected hAMSC

- Placental hAMSC

(d)
LEAK

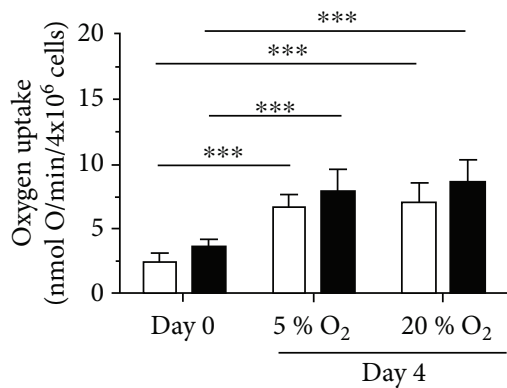

(b)

netROUTINE control ratio

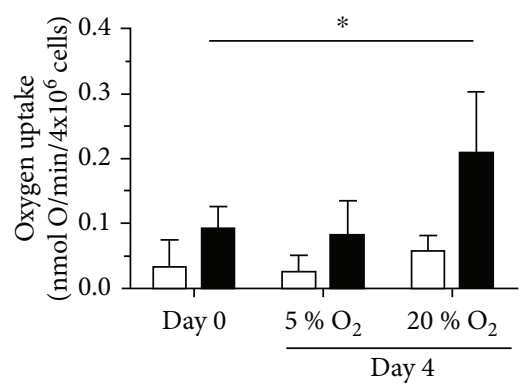

(e)
ETS capacity

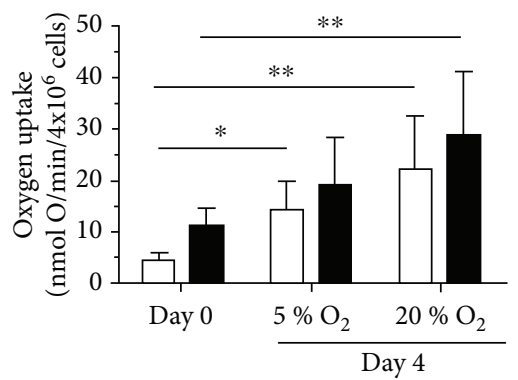

(c)

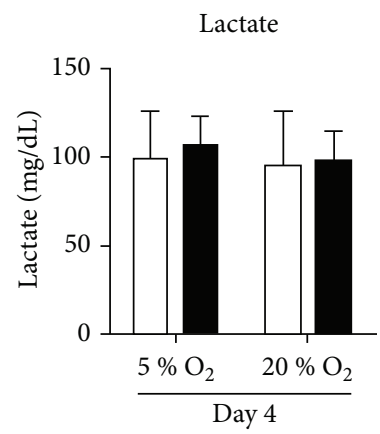

FIGURE 1: Mitochondrial activity and glycolysis. Mitochondrial respiration was measured in freshly isolated hAMSCs (day 0) and after 4-day incubation at $5 \%$ and $20 \%$ oxygen (a)-(e). Lactate in the cell culture supernatant was measured at day 4 (5\% and 20\% oxygen) (f). Cultivation of hAMSCs at $5 \%$ and $20 \%$ oxygen for 4 days led to elevated ROUTINE respiration (a), LEAK (b), and ETS capacity (c) for both oxygen concentrations but no difference in lactate production (f). Phosphorylation-related respiration was significantly increased only in samples incubated at $20 \%$ oxygen (d). This switch to oxidative phosphorylation in hAMSCs incubated at $20 \%$ oxygen was confirmed by the netROUTINE control ratio (e) which increases upon stimulation of oxidative phosporylation. $n=5-7$ (biological replicates), mean \pm SD. Abbreviations: ETS: electron transfer system; hAMSCs: human amniotic mesenchymal stromal cells; $\mathrm{O}_{2}$ : oxygen.

quantity of mitochondrial activity, we measured ROUTINE respiration, reflecting the aerobic metabolic activity. Cultivation of hAMSCs at $5 \% \mathrm{O}_{2}$ and $20 \% \mathrm{O}_{2}$ for 4 days lead to a significant increase of ROUTINE respiration for both oxygen concentrations. Values were always higher in placental amnion hAMSCs, and the effect was most pronounced in P-hAMSCs incubated at $20 \% \mathrm{O}_{2}$ (Figure $1(\mathrm{a})$ ).

To determine changes in the quality of mitochondrial activity, we first measured the LEAK state, reflecting proton pumping of the electron transport chain without producing ATP. We observed increased LEAK respiration after 4-day incubation, independent of the oxygen tension and the amniotic region (Figure 1(b)).

Determination of the maximum capacity of the mitochondrial electron transfer system (ETS) showed a similar picture as ROUTINE respiration. The increase in maximum capacity was oxygen-dependent, reaching the highest values in P-hAMSCs incubated at $20 \% \mathrm{O}_{2}$ (Figure 1 (c)).

Calculation of the phosphorylation-related respiration showed a drastic increase in cells incubated at $20 \% \mathrm{O}_{2}$, and this effect was most pronounced in hAMSCs of placental amnion (Figure 1(d)).
To see which fraction of ETS capacity is utilized to drive the phosphorylation of ADP to ATP, we calculated the "net ROUTINE control ratio" by dividing the phosphorylationrelated respiration by the ETS capacity. The strongest increase was observed in P-hAMSCs cultivated at $20 \% \mathrm{O}_{2}$, indicating that a higher proportion of ETS capacity is utilized to drive ATP synthesis in these cells (Figure 1(e)).

Concentrations of lactate in the cell culture supernatants were measured at day 4 , which were neither influenced by the oxygen tension nor the amniotic region (Figure 1(f)).

3.2. Measurement of ATP. ATP concentrations in hAMSCs after 4 days in culture increased compared to day 0 with both oxygen concentrations (Supplemental Figure 2).

3.3. Counting the Cellular mtDNA Copy Numbers. To estimate if the increase in mitochondrial respiration is due to an increase of the cellular mitochondrial content, the mtDNA copies per cell were counted. We observed a trend to an increasing mtDNA copy number in RA-hAMSCs (Figure 2(a)) and P-hAMSC (Figure 2(b)) incubated in $20 \%$, but this increase was not significant. 
Reflected hAMSC

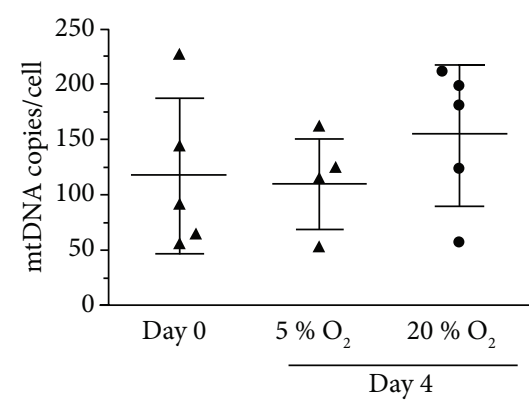

(a)

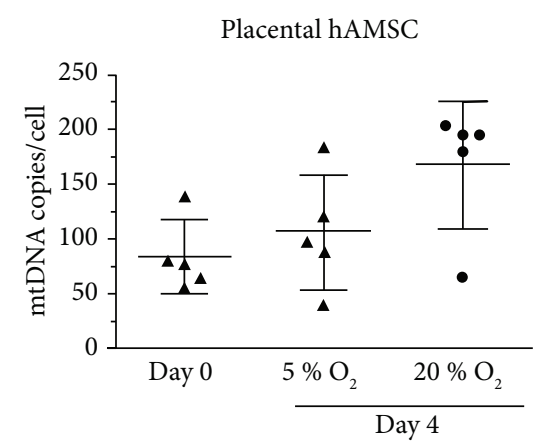

(b)

FIGURE 2: Cellular mitochondrial DNA copy number. The mtDNA copy number per cell was measured by digital PCR in freshly isolated human amniotic mesenchymal stromal cells (day 0) and after 4 days (5\% and 20\% oxygen) (a) and (b). We observed a trend to an increasing mtDNA copy number in samples incubated at $20 \%$ oxygen, but this increase was not significant. $n=5$ (biological replicates), mean \pm SD.

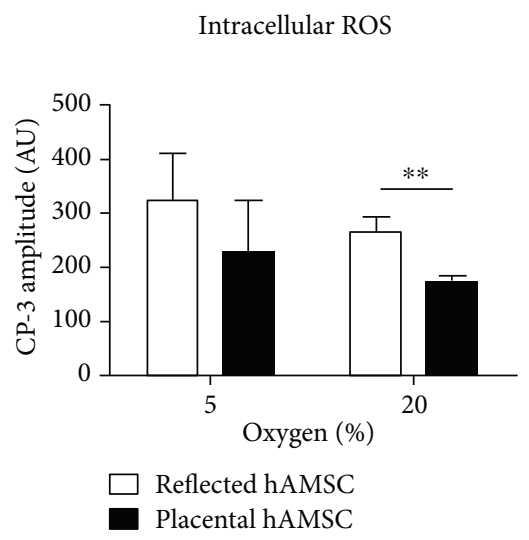

(a)

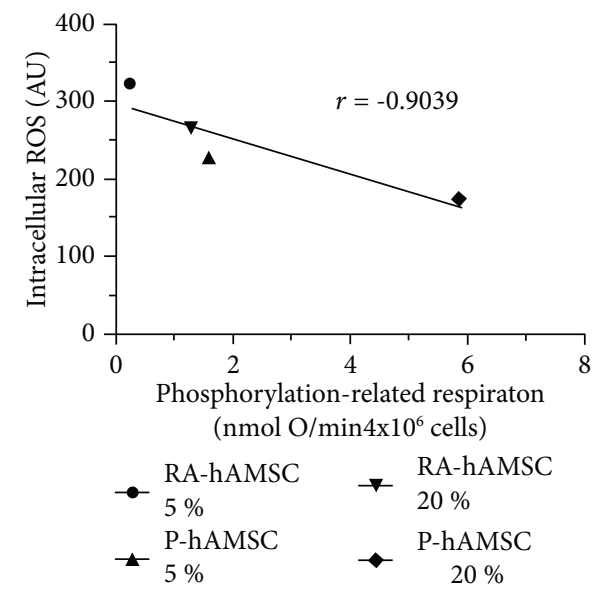

(b)

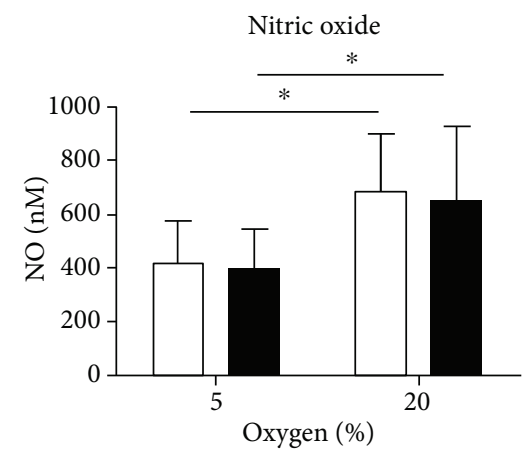

Reflected hAMSC

Placental hAMSC

(c)

Figure 3: Reactive oxygen and nitrogen species. Intracellular reactive oxygen species levels and nitric oxide levels were measured after 4 days incubation at $5 \%$ and $20 \%$ oxygen (a)-(c). No significant differences in ROS levels between $5 \%$ and $20 \%$ oxygen samples were observed (a). hAMSCs from placental amnion showed significantly lower levels of intracellular ROS (a). Calculation of correlation coefficient showed a strong negative association $(r=-0.9039)$ between intracellular ROS levels and phosphorylation-related respiration (b). Increased nitric oxide release was detected in cell culture supernatants of samples incubated at $20 \%$ oxygen (c). $n=5$ (biological replicates), mean \pm SD. Abbreviations: hAMSCs: human amniotic mesenchymal stromal cells; ROS: reactive oxygen species; RA: reflected amnion; P: placental amnion.

\subsection{Generation of Reactive Oxygen and Nitrogen Species.} Against our expectations, EPR measurement showed a trend to lower levels of intracellular ROS in hAMSCs incubated at higher oxygen tension. Furthermore, at 20\% oxygen, we detected significantly lower levels of intracellular ROS in PhAMSCs compared to RA-hAMSC (Figure 3(a)). Calculation of correlation between levels of intracellular ROS and phosphorylation-related respiration revealed a strong negative correlation $(r=-0.9039)$ between these parameters (Figure 3(b)).

Levels of nitric oxide in the supernatant of the cells showed significant differences between $5 \%$ and $20 \% \mathrm{O}_{2}$. However, within the same oxygen tension, no differences were found between cells of reflected and placental amnions (Figure 3(c)).
3.5. Release of Immunoactive Substances. Measurement of immunoactive substances after 4 days showed significantly higher concentrations of IL-6 in the cell culture supernatant of hAMSCs of placental amnion compared to hAMSCs from reflected amnion (Figure 4(a)). Oxygen tension impacted P-derived hAMSCs to secrete higher levels of IL- 6 when incubated at $20 \% \mathrm{O}_{2}$ compared to $5 \% \mathrm{O}_{2}$ (Figure $4(\mathrm{a})$ ). A similar pattern was observed when measuring IL-10 release, but significant differences between reflected and placental amnions were only found when cells were incubated at $20 \%$ oxygen (Figure 4(b)). Oxygen tension did not impact the release of hepatocyte growth factor (HGF); however, hAMSCs from placental amnion released significantly more HGF compared to hAMSCs from reflected amnion (Figure $4(\mathrm{c})$ ). In cells of both regions, we detected 
IL-6

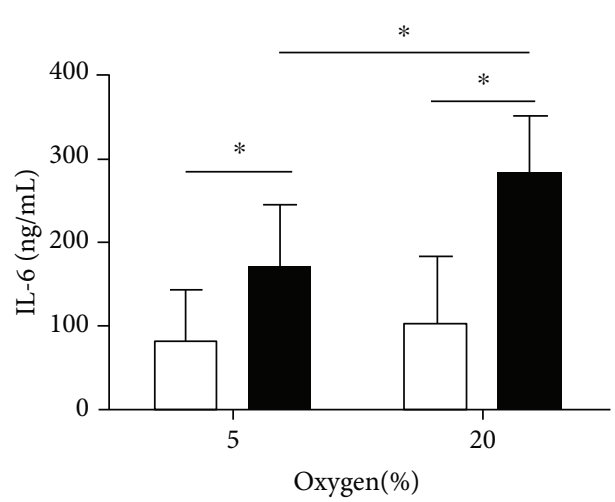

(a)

hepatocyte growth factor

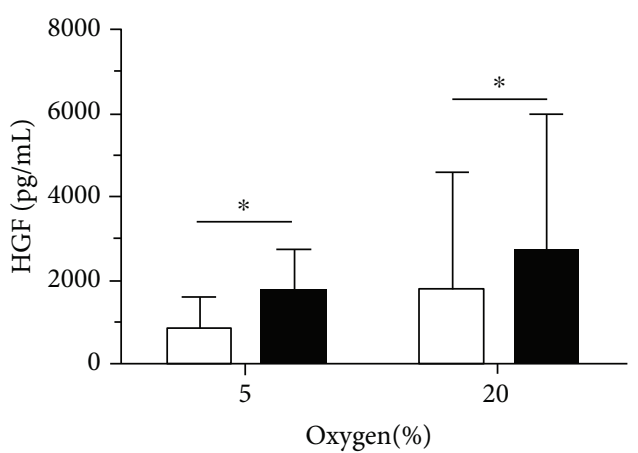

$\square$ Reflected hAMSC

Placental hAMSC
IL-10

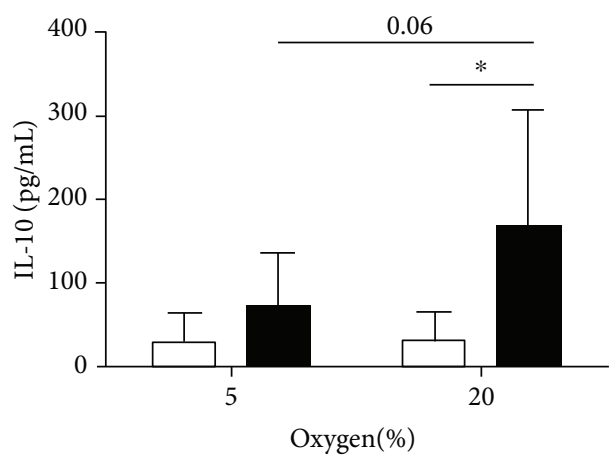

(b)

IL-1beta

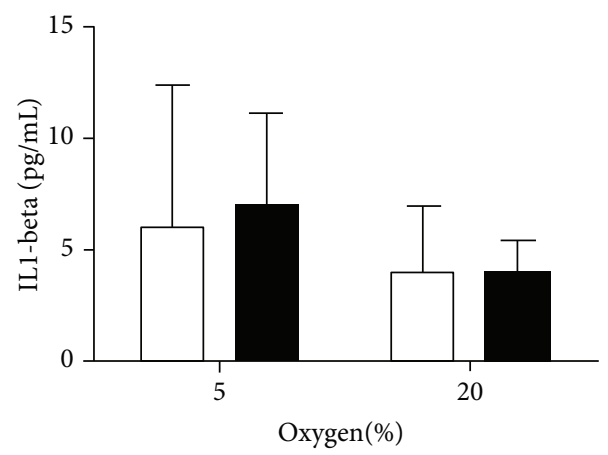

(d)

FIGURE 4: Release of immunoactive substances. Release of immunoactive substances in the cell culture supernatant of hAMSCs of reflected and placental amnion was measured after 4 days (5\% and 20\% oxygen) incubation (a)-(d). Higher oxygen tension (20\%) lead to significantly higher secretion of IL-6 (a) and a trend to higher IL-10 release (b) in hAMSCs from placental amnion and had no effect on the release of hepatocyte growth factor (c) and IL1-beta release (d) compared to lower oxygen tension (5\%). Cells from placental amnion released more IL-6 (a), IL10 (b) and hepatocyte growth factor (c) when compared within cultures at same oxygen concentrations (5\% and $20 \%$ oxygen). $n=6$ (biological replicates), mean \pm SD. Abbreviations: hAMSCs: human amniotic mesenchymal stromal cells; IL: interleukin.

very low concentrations of IL-1beta independent of the applied oxygen tension (Figure $4(\mathrm{~d})$ ).

\section{Discussion}

Cultivation of stem cells poses a great challenge, since maintenance of stemness requires niches with very low oxygen tensions. Common cell culture laboratories are usually set up for cultivation at $20 \%$ oxygen. Mitochondria are the main oxygen consumers, thereby providing energy via oxidative phosphorylation. Of note, stem cells acquire energy through ATP generation via glycolysis, and the metabolic switch from glycolysis to oxidative phosphorylation changes stem cell fate and cell function (reviewed in [23]).

Many research groups have experimented with bone marrow-derived or adipose tissue-derived mesenchymal stem cells under low or atmospheric oxygen tensions [17, 56-58]. Yet, to our knowledge, the influence of low and high oxygen tensions on hAMSCs under cell culture conditions and especially on their mitochondrial function has not been investigated. Furthermore, as the anti-inflammatory properties of the hAM could be critical in a clinical transplantation situation, we also measured parameters linked to inflammation.

Our data show that the mitochondrial metabolism of freshly isolated hAMSCs in culture is highly sensitive to surrounding oxygen levels. ROUTINE respiration (=LEAK state + phosphorylation-related respiration), reflecting total mitochondrial oxygen consumption, was increased in cultures of reflected amnion-derived hAMSCs (RA-hAMSCs) and placental amnion-derived hAMSCs (P-hAMSCs) in an oxygendependent manner. This increase came on one hand from an increase in LEAK state. On the other hand, incubation at $20 \%$ oxygen accelerated energy production via oxidative phosphorylation which was demonstrated by phosphorylationrelated respiration and the netROUTINE control ratio. Interestingly, this effect was more pronounced in hAMSCs derived from placental amnion. This is in line with previous reports, suggesting the need for low oxygen cell culture conditions, similar to the physiological stem cell niche [59]. 
The idea to use mitochondrial parameters such as respiratory function as an index for stem cell competence was postulated previously $[60,61]$. Our findings confirm that mitochondria-linked considerations should be taken into account in the proceedings of cell therapy in regenerative medicine to ensure quality of therapeutic cells.

We found that the LEAK state, reflecting proton permeability of the inner mitochondrial membrane without producing ATP, increased after 4-day incubation, independent of the oxygen tension and the amniotic region. Such an increase could be caused by different capacities of the electron transfer system (complex I-IV) in different microenvironments. This can be excluded in our study, as stimulation of maximal ETS capacity showed similar increases. Increased ROS production [62] is also unlikely, as we found lower levels of ROS. Interestingly, in stem cells, uncoupling proteins prevent mitochondrial glucose oxidation in response to high substrate concentration and thereby prevent ROS accumulation [63]. Therefore, our results can be explained by the high substrate concentration in common cell culture media compared to in vivo conditions. These results indicate that not only nonphysiological oxygen tensions but also nonphysiological substrate concentrations can change the cellular metabolism. We will focus on this matter in future studies.

Lactate concentrations in the supernatants were not influenced by oxygen tension, neither in reflected nor in placental amnion. This is not surprising since $5 \%$ oxygen is considered to be the physiological oxygen tension for amniotic cells. In addition, lactate concentrations are more often influenced by other factors than oxygen levels (reviewed in [64]).

Similarly, ATP concentrations are also influenced by many factors. We measured ATP concentrations of freshly isolated hAMSCs, as well as after cultivation at 5\% and $20 \%$ oxygen tensions for 4 days. We found an increase of ATP concentrations after 4 days of culture, compared to freshly isolated cells. However, the net cellular ATP concentrations represent a steady state between synthesis and consumption. Therefore, ATP concentrations do not reflect actual mitochondrial activity (reviewed in $[65,66]$ ).

We further found a trend to increasing mtDNA copy numbers in P-hAMSCs incubated at $20 \%$ oxygen, which is similar to an observation by Chen et al., who found increasing mtDNA copy numbers concomitant with an increasing oxygen consumption rate in the early phase of osteogenic induction [67]. In our study, the data suggest that the higher phosphorylation-related respiration is not due to a higher cellular mitochondrial density but to a higher coupling efficiency between the mitochondrial electron transfer system (complex I-IV) and the ATP synthase.

Surprisingly, although mitochondrial oxidative phosphorylation was increased in hAMSCs incubated at high oxygen tension, we observed a trend to lower levels of intracellular ROS in these cells. Calculation of correlation between phosphorylation-related respiration and intracellular ROS revealed a strong negative correlation between these parameters. Such findings have also been found with bone marrowderived hMSCs [67]. The authors observed an increased oxygen consumption rate concomitant with decreased intracellular ROS levels. In addition, they detected upregulation of two mitochondrial antioxidant enzymes, manganese superoxide dismutase (Mn-SOD) and catalase [67], and could show that especially Mn-SOD was concurrently upregulated to prevent the accumulation of intracellular ROS.

Intracellular ROS such as superoxide $\left(\mathrm{O}_{2}{ }^{--}\right)$could also be inactivated by nitric oxide ( $\mathrm{NO}^{\circ}$ ), which, beside its vasodilatory and signalling functions, has also antioxidant effectiveness [68]. In our study, independent of the amniotic region, NO showed higher levels at $20 \%$ oxygen compared to $5 \%$ oxygen. This was not surprising, since $\mathrm{NO}^{\circ}$ is predominantly generated in the presence of oxygen [69], except enzymeindependent generation of nitrite occurring in tissues under ischemic conditons [70]. However, in order to develop its full antioxidant capacity, $\mathrm{NO}^{\circ}$ has to be present in excess compared to $\mathrm{O}_{2}{ }^{--}$[71]. In contrast, equimolar concentrations of $\mathrm{NO}$ and $\mathrm{O}_{2}{ }^{--}$or excess of $\mathrm{O}_{2}{ }^{--}$can induce oxidative damage [71]. Thus, modulation of the balance between $\mathrm{O}_{2}{ }^{--}$and $\mathrm{NO}$ can be critical and may impact clinical applications.

For wound healing, increased NO generation could also be beneficial, as it has been shown to increase angiogenesis and improve neovascularization (reviewed in [72]). However, it can also activate matrix metalloproteinase- (MMP-) 9 (reviewed in [72]), which has been shown to play an important part in the spontaneous rupture of fetal membranes [73], possibly by its extracellular matrix-degrading activity. We suggest taking this fact into consideration while handling or cultivating the hAM under common cell culture conditions at $20 \%$ oxygen.

It is also important to note that excessive production of $\mathrm{NO}$ can cause inhibition of mitochondrial respiration, by irreversibly binding to complex I [74] or reversibly binding to complex IV [75]. Such excessive generation of NO occurs in response to inflammatory stimuli, which cause the upregulation of iNOS via nuclear factor- (NF-) $\kappa \mathrm{B}$ or signal transducers and activators of transcription- (STAT-) dependent pathways [76].

Regarding parameters linked to inflammation, high oxygen tension showed the strongest effect on P-derived hAMSCs, which secreted significantly more IL-6, when incubated at 20\% oxygen without any additional inflammatory challenge, compared to $5 \%$ oxygen. Similar results were found in a recent study with fetal membranes [77], which however, did not analyze reflected and placental amnions separately. IL-6 has been shown to inhibit proliferation of T cells [78] and, interestingly, also human amniotic epithelial cells [79]. Furthermore, Kumar et al. found proinflammatory cytokines in amniotic fluid to induce collagen remodelling, apoptosis, and weakening of cultured human fetal membranes [80]. The differences between the amniotic regions are more pronounced than the influence of the oxygen tension. Placenta-derived hAMSC secreted more IL-6, IL-10, and HGF compared to hAMSC of the reflected region. These data corroborate previous studies, where we and others already showed evidence of regional differences of the hAM [52, 53, 81-85]. In our latter report, we determined for the first time different mtDNA copy numbers in cells of the same type taken from different anatomical regions of the same individual, thus demonstrating that even at a normal physiological state, the cellular mtDNA copy number is tightly controlled not only in a cell type-specific but also in 
a region-specific manner [53]. Epigenetic regulation of the nuclear and/or mitochondrial genomes represents one of the putative factors that should be studied with regard to these regional alterations of the cellular mtDNA content considering that epigenetic marks are cell-type specific $[86,87]$ and that demethylation of specific mtDNA sites may cause an elevation of its copy number [88].

We hypothesize that the different anatomical locations of the amniotic regions, one covering the placenta, the other opposite of it, may be the cause for the differences observed. The two different areas may carry out different biological tasks during pregnancy. Furthermore, placental amnion could be supplied with different amounts of oxygen and different patterns of nutrients than reflected amnion. It is, however, not entirely known, how the avascular amniotic membrane is provided with nutrients and oxygen. If oxygen is transferred by diffusion, then, in utero, more oxygen might diffuse to placental amnion compared to reflected amnion. This hypothesis is corroborated by the behaviour of mitochondria in human amniotic mesenchymal cells and human amniotic epithelial cells. Compared to reflected amnion, placental amniotic cells show higher phosphorylation-related respiration, a parameter strongly linked to aerobic energy generation [53].

In this study, we found placental amniotic cells to respond to oxygen more readily than reflected amniotic cells. This was seen not only with mitochondrial parameters but also with the release of NO and IL-6. Similar to NO, IL-6 can also act in a dual role (reviewed in [89]). As recently shown, beside its proinflammatory action, IL-6 can attenuate inflammation [90]. Thus, cultivation under a "nonphysiological" oxygen tension may also have beneficial consequences for cell-based therapy. Hence, we propose that amniotic regions and the influence of oxygen should be taken into account for the cell cultivation for clinical applications of the hAM.

\section{Conclusion}

Taken together, we could show that even short-time cultivation ( 4 days) at common cell culture conditions (20\% oxygen) of freshly isolated hAMSC induced significant changes in mitochondrial function and the release of IL-6. Furthermore, the impact of high oxygen tension can be different, depending on the amniotic region, reflected or placental. Investigation of some selected parameters already showed that cultivation conditions can strongly influence cell physiology.

Mitochondrial activity and immunoactive factors are tightly interconnected with fundamental cellular processes involved in tissue regeneration. These distinctly different properties should be taken into consideration for clinical applications of amniotic cells. Depending on the therapeutic purpose, cultivation conditions of the cells should be chosen carefully for providing the best possible quality of cell therapy.

\section{Abbreviations}

$\begin{array}{ll}\text { ATP: } & \text { Adenosine triphosphate } \\ \text { CP-H: } & \text { Cyclic hydroxylamine 1-hydroxy-3-carboxy- } \\ & \text { 2,2,5,5-tetramethylpyrrolidine hydrochloride } \\ \text { EPR: } & \text { Electron paramagnetic resonance }\end{array}$

ETS: $\quad$ Electron transfer system

hAM: Human amniotic membrane

hAMSCs: Human amniotic mesenchymal stromal cells

HGF: $\quad$ Hepatocyte growth factor

IL: Interleukin

iNOS: $\quad$ Inducible nitric oxide synthase

MMP: $\quad$ Matrix metalloproteinase

Mn-SOD: Manganese superoxide dismutase

mtDNA: $\quad$ Mitochondrial DNA

NF: $\quad$ Nuclear factor

P-hAMSCs: Placental amnion-derived hAMSCs

RA-hAMSCs: Reflected amnion-derived hAMSCs

ROS: $\quad$ Reactive oxygen species

STAT: $\quad$ Signal transducers and activators of transcription.

\section{Data Availability}

The data used to support the findings of this study are available from the corresponding author upon request.

\section{Conflicts of Interest}

The authors declare that there is no conflict of interest regarding the publication of this article.

\section{Acknowledgments}

We acknowledge Philipp Steindorf (VetCore, Vetmeduni Vienna) and Mohammad Jafarmadar for technical assistance. This work was partly supported by the European Union's Horizon 2020 research and innovation program "Arrest Blindness" (grant number 667400) and Österreichische Forschungsförderungsgesellschaft (FFG, grant number 854180).

\section{Supplementary Materials}

Supplemental Table 1: oligonucleotide sequences of quantitative PCR and digital PCR. Supplemental Figure 1: mitochondrial activity measurement. Representative oxygen consumption trace of placental hAMSCs incubated for 4 days at $20 \%$ oxygen (P, blue), and reflected hAMSCs incubated for 4 days at $5 \%$ oxygen (RA, magenta). 1 = ROUTINE respiration, $2=$ LEAK, 3 (D1-2) = phosphorylation-related respiration. Abbreviations: hAMSCs, human amniotic mesenchymal stromal cells. Supplemental Figure 2: adenosine triphosphate concentration (ATP). ATP concentration wasmeasured in 100000 freshly isolated hAMSCs at day 0 , and after 4 days incubation at $5 \%$ and 20 $\%$ oxygen. The cells were homogenized and ATP was determined using luciferase reagent with Luminat LB9507. $\mathrm{n}=3-5$ (biological replicates), mean $\pm \mathrm{SD},{ }^{*} p<0.05$ vs day 0 . Abbreviations: hAMSCs, humanamniotic mesenchymal stromal cells; O2, oxygen. (Supplementary Materials)

\section{References}

[1] P. B. Wignall and R. J. Twitchett, "Oceanic anoxia and the End Permian Mass Extinction," Science, vol. 272, no. 5265, pp. 1155-1158, 1996. 
[2] D. Yang, X. Guo, T. Xie, and X. Luo, "Reactive oxygen species may play an essential role in driving biological evolution: the Cambrian Explosion as an example," Journal of Environmental Sciences (China), vol. 63, pp. 218-226, 2018.

[3] L. Sagan, "On the origin of mitosing cells," Journal of Theoretical Biology, vol. 14, no. 3, pp. 225-IN6, 1967.

[4] M. W. Gray, "Lynn Margulis and the endosymbiont hypothesis: 50 years later," Molecular Biology of the Cell, vol. 28, no. 10, pp. 1285-1287, 2017.

[5] A. Dyson and M. Singer, "Tissue oxygen tension monitoring: will it fill the void?," Current Opinion in Critical Care, vol. 17, no. 3, pp. 281-289, 2011.

[6] Z. Ivanovic, "Hypoxia or in situ normoxia: the stem cell paradigm," Journal of Cellular Physiology, vol. 219, no. 2, pp. 271-275, 2009.

[7] V. De Santis and M. Singer, "Tissue oxygen tension monitoring of organ perfusion: rationale, methodologies, and literature review," British Journal of Anaesthesia, vol. 115, no. 3, pp. 357-365, 2015.

[8] D. C. Chow, L. A. Wenning, W. M. Miller, and E. T. Papoutsakis, "Modeling pO2 distributions in the bone marrow hematopoietic compartment. II. Modified Kroghian models," Biophysical Journal, vol. 81, no. 2, pp. 685-696, 2001.

[9] J. A. Spencer, F. Ferraro, E. Roussakis et al., "Direct measurement of local oxygen concentration in the bone marrow of live animals," Nature, vol. 508, no. 7495, pp. 269-273, 2014.

[10] M. Jež, P. Rožman, Z. Ivanović, and T. Bas, "Concise review: the role of oxygen in hematopoietic stem cell physiology," Journal of Cellular Physiology, vol. 230, no. 9, pp. 1999-2005, 2015.

[11] K. Ito and K. Ito, "Metabolism and the control of cell fate decisions and stem cell renewal," Annual Review of Cell and Developmental Biology, vol. 32, no. 1, pp. 399-409, 2016.

[12] S. Chung, P. P. Dzeja, R. S. Faustino, C. Perez-Terzic, A. Behfar, and A. Terzic, "Mitochondrial oxidative metabolism is required for the cardiac differentiation of stem cells," Nature Clinical Practice. Cardiovascular Medicine, vol. 4, Supplement 1, pp. S60-S67, 2007.

[13] H. Kondoh, M. E. Lleonart, Y. Nakashima et al., "A high glycolytic flux supports the proliferative potential of murine embryonic stem cells," Antioxidants \& Redox Signaling, vol. 9, no. 3, pp. 293-299, 2007.

[14] C. D. L. Folmes and A. Terzic, "Energy metabolism in the acquisition and maintenance of stemness," Seminars in Cell \& Developmental Biology, vol. 52, pp. 68-75, 2016.

[15] L. Basciano, C. Nemos, B. Foliguet et al., "Long term culture of mesenchymal stem cells in hypoxia promotes a genetic program maintaining their undifferentiated and multipotent status," BMC Cell Biology, vol. 12, no. 1, p. 12, 2011.

[16] P. H. Oliveira, J. S. Boura, M. M. Abecasis, J. M. Gimble, C. L. da Silva, and J. M. S. Cabral, "Impact of hypoxia and long-term cultivation on the genomic stability and mitochondrial performance of ex vivo expanded human stem/stromal cells," Stem Cell Research, vol. 9, no. 3, pp. 225-236, 2012.

[17] C. Fotia, A. Massa, F. Boriani, N. Baldini, and D. Granchi, "Prolonged exposure to hypoxic milieu improves the osteogenic potential of adipose derived stem cells," Journal of Cellular Biochemistry, vol. 116, no. 7, pp. 1442-1453, 2015.

[18] D. S. Kim, Y. J. Ko, M. W. Lee et al., "Effect of low oxygen tension on the biological characteristics of human bone marrow mesenchymal stem cells," Cell Stress \& Chaperones, vol. 21, no. 6, pp. 1089-1099, 2016.
[19] Y. Yoshida, K. Takahashi, K. Okita, T. Ichisaka, and S. Yamanaka, "Hypoxia enhances the generation of induced pluripotent stem cells," Cell Stem Cell, vol. 5, no. 3, pp. 237241, 2009.

[20] R. Schofield, "The relationship between the spleen colonyforming cell and the haemopoietic stem cell," Blood Cells, vol. 4, no. 1-2, pp. 7-25, 1978.

[21] F. Ferraro, C. L. Celso, and D. Scadden, "Adult stem cells and their niches," Advances in Experimental Medicine and Biology, vol. 695, pp. 155-168, 2010.

[22] A. Kumar, J. K. Placone, and A. J. Engler, "Understanding the extracellular forces that determine cell fate and maintenance," Development, vol. 144, no. 23, pp. 4261-4270, 2017.

[23] A. Wanet, T. Arnould, M. Najimi, and P. Renard, "Connecting mitochondria, metabolism, and stem cell fate," Stem Cells and Development, vol. 24, no. 17, pp. 1957-1971, 2015.

[24] O. Parolini, F. Alviano, G. P. Bagnara et al., "Concise review: isolation and characterization of cells from human term placenta: outcome of the first international workshop on placenta derived stem cells," Stem Cells, vol. 26, no. 2, pp. 300-311, 2008.

[25] M. Stern, "The grafting of preserved amniotic membrane to burned and ulcerated surfaces, substituing skin grafts," Journal of the American Medical Association, vol. 60, no. 13, p. 973, 1913.

[26] N. Sabella, "Use of the fetal membranes in skin grafting," Medical Record, vol. 13, no. 3, 1913.

[27] T. Miki and S. C. Strom, "Amnion-derived pluripotent/multipotent stem cells," Stem Cell Reviews, vol. 2, no. 2, pp. 133-141, 2006.

[28] K. Satoh, T. Yasumizu, Y. Kawai et al., "In vitro production of prostaglandins E, F, and 6-keto prostaglandin F1 alpha by human pregnant uterus, decidua and amnion," Prostaglandins and Medicine, vol. 6, no. 4, pp. 359-368, 1981.

[29] Y. Hao, D. H.-K. Ma, D. G. Hwang, W.-S. Kim, and F. Zhang, "Identification of antiangiogenic and antiinflammatory proteins in human amniotic membrane," Cornea, vol. 19, no. 3, pp. $348-352,2000$.

[30] J. S. Kim, J. C. Kim, B. K. Na, J. M. Jeong, and C. Y. Song, "Amniotic membrane patching promotes healing and inhibits proteinase activity on wound healing following acute corneal alkali burn," Experimental Eye Research, vol. 70, no. 3, pp. 329-337, 2000.

[31] M. Bailo, M. Soncini, E. Vertua et al., "Engraftment potential of human amnion and chorion cells derived from term placenta," Transplantation, vol. 78, no. 10, pp. 1439-1448, 2004.

[32] H. Li, J. Y. Niederkorn, S. Neelam et al., "Immunosuppressive factors secreted by human amniotic epithelial cells," Investigative Ophthalmology and Visual Science, vol. 46, no. 3, pp. 900907, 2005.

[33] S. Wolbank, A. Peterbauer, M. Fahrner et al., "Dose-dependent immunomodulatory effect of human stem cells from amniotic membrane: a comparison with human mesenchymal stem cells from adipose tissue," Tissue Engineering, vol. 13, no. 6, pp. 1173-1183, 2007.

[34] G. Raicevic, M. Najar, B. Stamatopoulos et al., "The source of human mesenchymal stromal cells influences their TLR profile as well as their functional properties," Cellular Immunology, vol. 270, no. 2, pp. 207-216, 2011.

[35] B. Kronsteiner, A. Peterbauer-Scherb, R. Grillari-Voglauer et al., "Human mesenchymal stem cells and renal tubular epithelial cells differentially influence monocyte-derived dendritic 
cell differentiation and maturation," Cellular Immunology, vol. 267, no. 1, pp. 30-38, 2011.

[36] M. Ohshima, K. Yamahara, S. Ishikane et al., "Systemic transplantation of allogenic fetal membrane-derived mesenchymal stem cells suppresses Th1 and Th17 T cell responses in experimental autoimmune myocarditis," Journal of Molecular and Cellular Cardiology, vol. 53, no. 3, pp. 420428, 2012.

[37] M. Magatti, S. de Munari, E. Vertua, L. Gibelli, G. S. Wengler, and O. Parolini, "Human amnion mesenchyme harbors cells with allogeneic T-cell suppression and stimulation capabilities," Stem Cells, vol. 26, no. 1, pp. 182-192, 2008.

[38] M. Magatti, S. De Munari, E. Vertua et al., "Amniotic mesenchymal tissue cells inhibit dendritic cell differentiation of peripheral blood and amnion resident monocytes," Cell Transplantation, vol. 18, no. 8, pp. 899-914, 2009.

[39] B. Kronsteiner, S. Wolbank, A. Peterbauer et al., "Human mesenchymal stem cells from adipose tissue and amnion influence T-cells depending on stimulation method and presence of other immune cells," Stem Cells and Development, vol. 20, no. 12, pp. 2115-2126, 2011.

[40] N. Sakuragawa, R. Thangavel, M. Mizuguchi, M. Hirasawa, and I. Kamo, "Expression of markers for both neuronal and glial cells in human amniotic epithelial cells," Neuroscience Letters, vol. 209, no. 1, pp. 9-12, 1996.

[41] K. Kakishita, N. Nakao, N. Sakuragawa, and T. Itakura, "Implantation of human amniotic epithelial cells prevents the degeneration of nigral dopamine neurons in rats with 6hydroxydopamine lesions," Brain Research, vol. 980, no. 1, pp. $48-56,2003$.

[42] S. Takashima, H. Ise, P. Zhao, T. Akaike, and T. Nikaido, "Human amniotic epithelial cells possess hepatocyte-like characteristics and functions," Cell Structure and Function, vol. 29, no. 3, pp. 73-84, 2004.

[43] T. Miki, T. Lehmann, H. Cai, D. B. Stolz, and S. C. Strom, "Stem cell characteristics of amniotic epithelial cells," Stem Cells, vol. 23, no. 10, pp. 1549-1559, 2005.

[44] C. B. Portmann-Lanz, A. Schoeberlein, A. Huber et al., "Placental mesenchymal stem cells as potential autologous graft for pre- and perinatal neuroregeneration," American Journal of Obstetrics and Gynecology, vol. 194, no. 3, pp. 664-673, 2006.

[45] E. E. van Faassen, S. Bahrami, M. Feelisch et al., "Nitrite as regulator of hypoxic signaling in mammalian physiology," Medicinal Research Reviews, vol. 29, no. 5, pp. 683-741, 2009.

[46] M. P. Murphy, "How mitochondria produce reactive oxygen species," The Biochemical Journal, vol. 417, no. 1, pp. 1-13, 2009.

[47] A. V. Kozlov, J. R. Lancaster Jr, A. T. Meszaros, and A. Weidinger, "Mitochondria-meditated pathways of organ failure upon inflammation," Redox Biology, vol. 13, pp. 170181, 2017.

[48] A. Weidinger and A. Kozlov, "Biological activities of reactive oxygen and nitrogen species: oxidative stress versus signal transduction," Biomolecules, vol. 5, no. 2, pp. 472-484, 2015.

[49] E. Berger, E. Rath, D. Yuan et al., "Mitochondrial function controls intestinal epithelial stemness and proliferation," Nature Communications, vol. 7, pp. 1-17, 2016.

[50] C. Cherry, B. Thompson, N. Saptarshi, J. Wu, and J. Hoh, "2016: a 'mitochondria' odyssey," Trends in Molecular Medicine, vol. 22, no. 5, pp. 391-403, 2016.
[51] H. E. Johnell, B. A. Nilsson, and R. Tammivaara-Hilty, "Oxygen tension, carbon dioxide tension and $\mathrm{pH}$ in amniotic fluid and maternal arterial blood during induced maternal hyperoxia and hypoxia," Acta Obstetricia et Gynecologica Scandinavica, vol. 50, no. 3, pp. 209-214, 1971.

[52] A. Banerjee, A. Weidinger, M. Hofer et al., "Different metabolic activity in placental and reflected regions of the human amniotic membrane," Placenta, vol. 36, no. 11, pp. 1329-1332, 2015.

[53] A. Banerjee, A. Lindenmair, S. Hennerbichler et al., "Cellular and site-specific mitochondrial characterization of vital human amniotic membrane," Cell Transplantation, vol. 27, no. 1, pp. 3-11, 2018.

[54] A. V. Kozlov, L. Szalay, F. Umar et al., "EPR analysis reveals three tissues responding to endotoxin by increased formation of reactive oxygen and nitrogen species," Free Radical Biology \& Medicine, vol. 34, no. 12, pp. 1555-1562, 2003.

[55] A. Weidinger, A. Müllebner, J. Paier-Pourani et al., "Vicious inducible nitric oxide synthase-mitochondrial reactive oxygen species cycle accelerates inflammatory response and causes liver injury in rats," Antioxidants \& Redox Signaling, vol. 22, no. 7, pp. 572-586, 2015.

[56] D. P. Lennon, J. M. Edmison, and A. I. Caplan, "Cultivation of rat marrow-derived mesenchymal stem cells in reduced oxygen tension: effects on in vitro and in vivo osteochondrogenesis," Journal of Cellular Physiology, vol. 187, no. 3, pp. 345-355, 2001.

[57] G. D'Ippolito, S. Diabira, G. A. Howard, B. A. Roos, and P. C. Schiller, "Low oxygen tension inhibits osteogenic differentiation and enhances stemness of human MIAMI cells," Bone, vol. 39, no. 3, pp. 513-522, 2006.

[58] Y. Yamamoto, M. Fujita, Y. Tanaka et al., "Low oxygen tension enhances proliferation and maintains stemness of adipose tissue-derived stromal cells," BioResearch Open Access, vol. 2, no. 3, pp. 199-205, 2013.

[59] T. Ezashi, P. Das, and R. M. Roberts, "Low $\mathrm{O}_{2}$ tensions and the prevention of differentiation of HES cells," Proceedings of the National Academy of Sciences, vol. 102, no. 13, pp. 47834788, 2005.

[60] J. M. G. Reyes, S. Fermanian, F. Yang et al., "Metabolic changes in mesenchymal stem cells in osteogenic medium measured by autofluorescence spectroscopy," Stem Cells, vol. 24, no. 5, pp. 1213-1217, 2006.

[61] H.-W. Guo, C.-T. Chen, Y.-H. Wei et al., "Reduced nicotinamide adenine dinucleotide fluorescence lifetime separates human mesenchymal stem cells from differentiated progenies," Journal of Biomedical Optics, vol. 13, no. 5, article 050505, 2008.

[62] V. P. Skulachev, "Uncoupling: new approaches to an old problem of bioenergetics," Biochimica et Biophysica Acta (BBA) Bioenergetics, vol. 1363, no. 2, pp. 100-124, 1998.

[63] J. Zhang, I. Khvorostov, J. S. Hong et al., "UCP2 regulates energy metabolism and differentiation potential of human pluripotent stem cells," The EMBO Journal, vol. 30, no. 24, pp. 4860-4873, 2011.

[64] B. S. Ferguson, M. J. Rogatzki, M. L. Goodwin, D. A. Kane, Z. Rightmire, and L. B. Gladden, "Lactate metabolism: historical context, prior misinterpretations, and current understanding," European Journal of Applied Physiology, vol. 118, no. 4, pp. 691-728, 2018.

[65] M. D. Brand and D. G. Nicholls, "Assessing mitochondrial dysfunction in cells," The Biochemical Journal, vol. 435, no. 2, pp. 297-312, 2011. 
[66] D. G. Nicholls and S. J. Ferguson, Bioenergetics 4, Elsevier, Academic Press, Amsterdam, 4th edition, 2013.

[67] C.-T. Chen, Y.-R. V. Shih, T. K. Kuo, O. K. Lee, and Y.-H. Wei, "Coordinated changes of mitochondrial biogenesis and antioxidant enzymes during osteogenic differentiation of human mesenchymal stem cells," Stem Cells, vol. 26, no. 4, pp. 960968, 2008.

[68] V. E. Kagan, A. V. Kozlov, Y. Y. Tyurina, A. A. Shvedova, and J. C. Yalowich, "Antioxidant mechanisms of nitric oxide against iron-catalyzed oxidative stress in cells," Antioxidants \& Redox Signaling, vol. 3, no. 2, pp. 189-202, 2001.

[69] N. S. Kwon, C. F. Nathan, C. Gilker, O. W. Griffith, D. E. Matthews, and D. J. Stuehr, "L-citrulline production from Larginine by macrophage nitric oxide synthase. The ureido oxygen derives from dioxygen," The Journal of Biological Chemistry, vol. 265, no. 23, pp. 13442-13445, 1990.

[70] J. L. Zweier, P. Wang, A. Samouilov, and P. Kuppusamy, "Enzyme-independent formation of nitric oxide in biological tissues," Nature Medicine, vol. 1, no. 8, pp. 804-809, 1995.

[71] F. Violi, R. Marino, M. T. Milite, and L. Loffredo, "Nitric oxide and its role in lipid peroxidation," Diabetes/Metabolism Research and Reviews, vol. 15, no. 4, pp. 283-288, 1999.

[72] K. M. Fosen and S. R. Thom, "Hyperbaric oxygen, vasculogenic stem cells, and wound healing," Antioxidants \& Redox Signaling, vol. 21, no. 11, pp. 1634-1647, 2014.

[73] N. Athayde, S. S. Edwin, R. Romero et al., "A role for matrix metalloproteinase-9 in spontaneous rupture of the fetal membranes," American Journal of Obstetrics and Gynecology, vol. 179, no. 5, pp. 1248-1253, 1998.

[74] G. C. Brown and V. Borutaite, "Inhibition of mitochondrial respiratory complex I by nitric oxide, peroxynitrite and Snitrosothiols," Biochimica et Biophysica Acta (BBA) - Bioenergetics, vol. 1658, no. 1-2, pp. 44-49, 2004.

[75] G. C. Brown and V. Borutaite, "Nitric oxide, cytochrome c and mitochondria," Biochemical Society Symposium, vol. 66, pp. 17-25, 1999.

[76] M. Farlik, B. Reutterer, C. Schindler et al., "Nonconventional initiation complex assembly by STAT and NF- $\kappa$ B transcription factors regulates nitric oxide synthase expression," Immunity, vol. 33, no. 1, pp. 25-34, 2010.

[77] M. Al-Asmakh, H. Race, S. Tan, and M. H. F. Sullivan, “The effects of oxygen concentration on in vitro output of prostaglandin E2 and interleukin-6 from human fetal membranes," MHR: Basic science of reproductive medicine, vol. 13, no. 3, pp. 197-201, 2007.

[78] D. Rossi, S. Pianta, M. Magatti, P. Sedlmayr, and O. Parolini, "Characterization of the conditioned medium from amniotic membrane cells: prostaglandins as key effectors of its immunomodulatory activity," PLoS One, vol. 7, no. 10, article e46956, 2012.

[79] S. Terada, K. Matsuura, S. Enosawa et al., "Inducing proliferation of human amniotic epithelial (HAE) cells for cell therapy," Cell Transplantation, vol. 9, no. 5, pp. 701-704, 2000.

[80] D. Kumar, W. Fung, R. M. Moore et al., "Proinflammatory cytokines found in amniotic fluid induce collagen remodeling, apoptosis, and biophysical weakening of cultured human fetal membranes," Biology of Reproduction, vol. 74, no. 1, pp. 29-34, 2006.
[81] Y. M. Han, R. Romero, J.-S. Kim et al., "Region-specific gene expression profiling: novel evidence for biological heterogeneity of the human amnion," Biology of Reproduction, vol. 79, no. 5, pp. 954-961, 2008.

[82] S. Y. Kim, R. Romero, A. L. Tarca et al., "miR-143 regulation of prostaglandin-endoperoxidase synthase 2 in the amnion: implications for human parturition at term," PLoS One, vol. 6, no. 9, article e24131, 2011.

[83] T. Deihim, G. Yazdanpanah, and H. Niknejad, "Different light transmittance of placental and reflected regions of human amniotic membrane that could be crucial for corneal tissue engineering," Cornea, vol. 35, no. 7, pp. 997-1003, 2016.

[84] M. Litwiniuk, M. Radowicka, A. Krejner, A. Śladowska, and T. Grzela, "Amount and distribution of selected biologically active factors in amniotic membrane depends on the part of amnion and mode of childbirth. Can we predict properties of amnion dressing? A proof-of-concept study," Central European Journal of Immunology, vol. 43, no. 1, pp. 97-102, 2018.

[85] L. Centurione, F. Passaretta, M. A. Centurione et al., "Mapping of the human placenta: experimental evidence of amniotic epithelial cell heterogeneity," Cell Transplantation, vol. 27, no. 1, pp. 12-22, 2018.

[86] R. Maruyama, S. Choudhury, A. Kowalczyk et al., "Epigenetic regulation of cell type-specific expression patterns in the human mammary epithelium," PLoS Genetics, vol. 7, no. 4, p. e1001369, 2011.

[87] M. Mito, M. Kadota, K. Tanaka et al., "Cell type-specific survey of epigenetic modifications by tandem chromatin immunoprecipitation sequencing," Scientific Reports, vol. 8, no. 1, pp. 1143-1114, 2018.

[88] H. Tong, L. Zhang, J. Gao, S. Wen, H. Zhou, and S. Feng, "Methylation of mitochondrial DNA displacement loop region regulates mitochondrial copy number in colorectal cancer," Molecular Medicine Reports, vol. 16, no. 4, pp. 5347-5353, 2017.

[89] A. J. Covarrubias and T. Horng, "IL-6 strikes a balance in metabolic inflammation," Cell Metabolism, vol. 19, no. 6, pp. 898899, 2014.

[90] J. Mauer, B. Chaurasia, J. Goldau et al., "Interleukin-6 signaling promotes alternative macrophage activation to limit obesity-associated insulin resistance and endotoxemia," Nature Immunology, vol. 15, no. 5, pp. 423-430, 2014. 


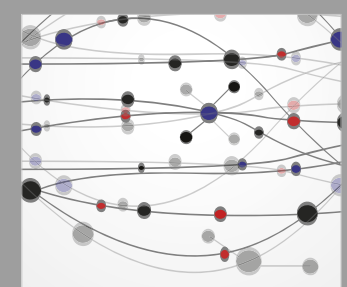

The Scientific World Journal
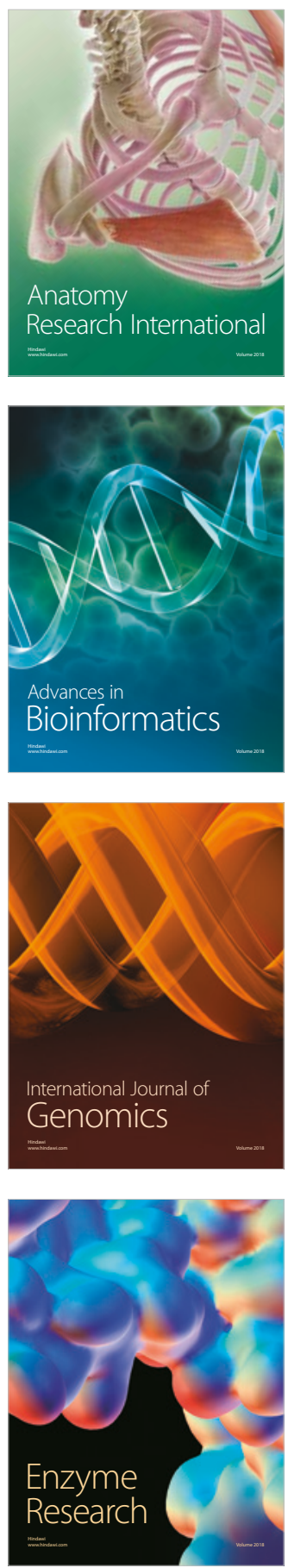
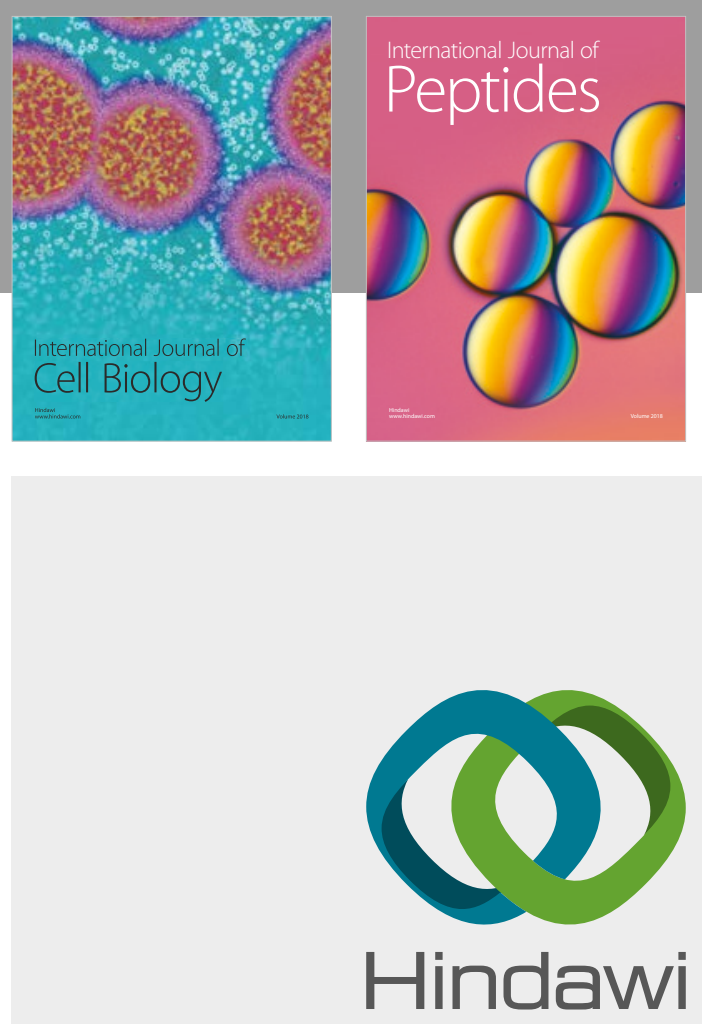

Submit your manuscripts at

www.hindawi.com
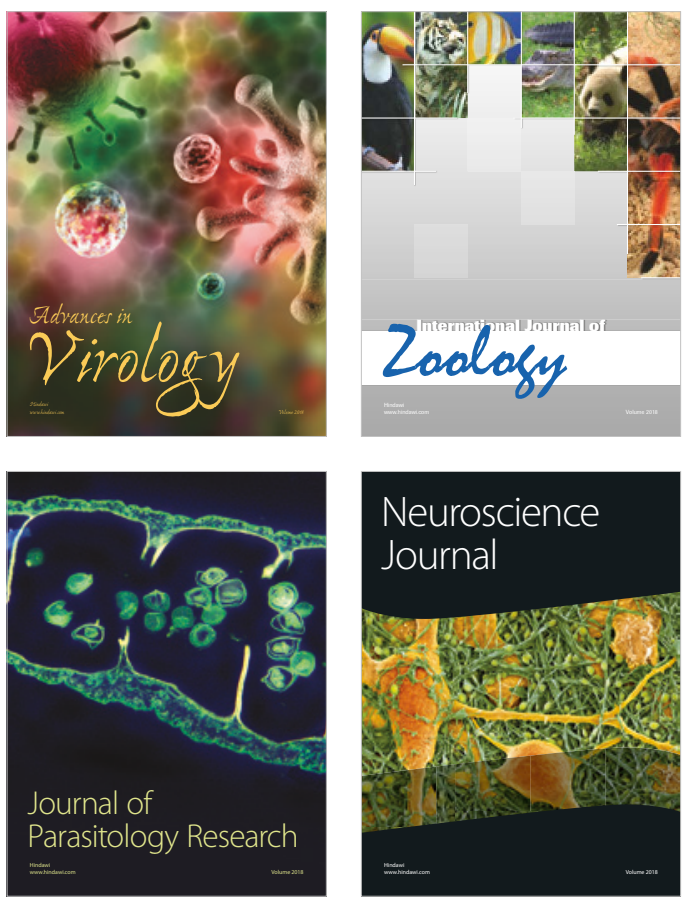
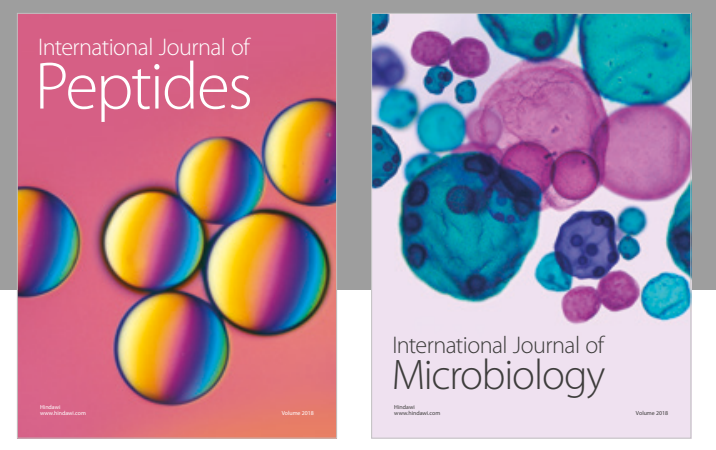

nternational Journal of Microbiology
Journal of
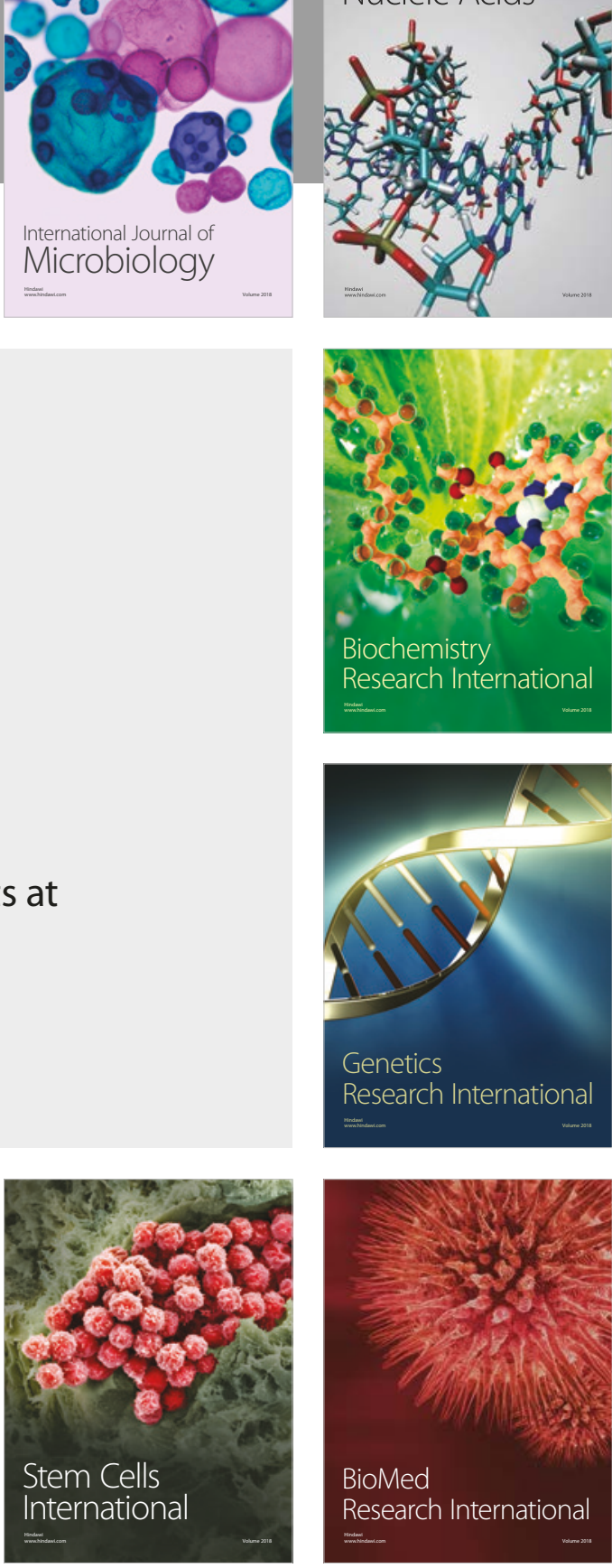
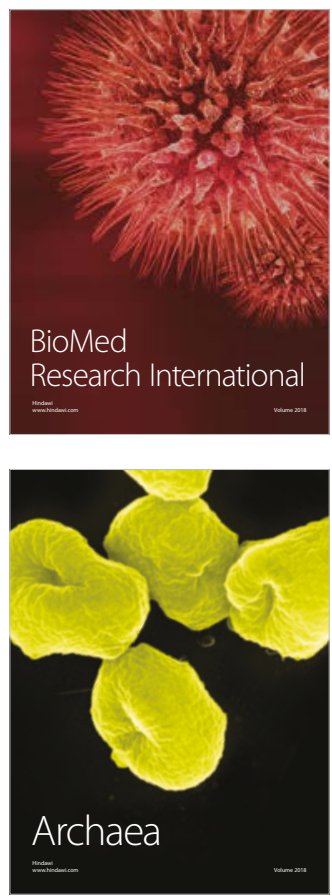